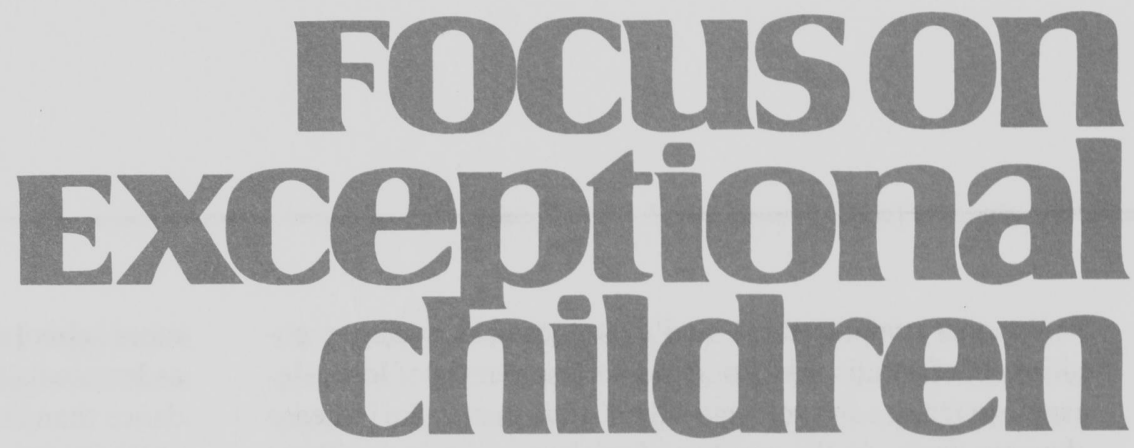

\title{
Management of Aggressive and Violent Behavior in the Schools
}

\author{
Robert B. Rutherford, Jr., and C. Michael Nelson
}

Aggressive and violent behaviors are increasing among children and youth in America's schools. Although many children and adolescents occasionally exhibit aggressive and sometimes antisocial behaviors in the course of development, an alarming increase is taking place in the significant number of youth who confront their parents, teachers, and schools with persistent threatening and destructive behaviors. Students who exhibit chronic patterns of hostile, aggressive, and defiant behaviors frequently are characterized as having oppositional disorders or conduct disorders (Kazdin, 1987; Horne \& Sayger, 1990), and their behaviors are increasingly identified as antisocial (Walker, Colvin, \& Ramsey, 1995).

The Diagnostic and Statistical Manual of Mental Disorders (DSM-III-R) (American Psychiatric Association, 1987) defines oppositional defiant disorder as

a pattern of negativistic, hostile, and defiant behavior. . . . Children with this disorder commonly are argumentative with adults, frequently lose their temper, swear, and are often angry, resentful, and easily annoyed by others. They frequently actively defy adult requests or rules and deliberately annoy other people. They tend to blame others for their own mistakes or difficulties. (p. 56)

Conduct disorder, a more serious and disruptive aggressive behavior pattern, is defined in the DSM-III-R as

a persistent pattern of conduct in which the basic rights of others and major age-appropriate societal norms or rules are violated. . . Physical aggression is common. Children and adolescents with this disorder usually initiate aggression, may be physically cruel to other people or animals, and frequently destroy other people's property. (p. 53)

Antisocial behavior has been defined as "recurrent violations of socially prescribed patterns of behavior" (Simcha-Fagan, Langner, Gersten, \& Eisenberg, 1975, p. 7), and antisocial patterns of behavior have been described as the polar opposite of prosocial patterns, which are composed of cooperative, positive, and mutually reciprocal social behaviors (Walker et al., 1995). According to Walker et al., "Antisocial behavior suggests hostility to others, aggression, a willingness to commit rule infractions, defiance of adult authority, and violation of the social norms and mores of society" (p. 2).

Robert Rutherford is a professor of special education at Arizona State University. Michael Nelson is a professor of special education at the University of Kentucky. 
Whether students are formally diagnosed as having oppositional defiant disorders or conduct disorders is of less relevance to many educators and school staff than is the increase they are seeing in the number of students, with and without formal diagnoses, who are exhibiting aggressive and violent antisocial behaviors in the schools. A substantial body of research indicates that antisocial behavior problems are significant and durable conditions in many children and adolescents (Nelson \& Rutherford, 1990). For example, from their series of longitudinal assessments of antisocial behavior of boys in school settings, Walker and his colleagues (Shinn, Ramsey, Walker, Stieber, \& O’Neill, 1987; Walker, Shinn, O'Neill, \& Ramsey, 1987; Walker, Stieber, \& O'Neill, 1990; Walker, Stieber, Ramsey, \& O’Neill, 1991) found that students who exhibited antisocial behavior experienced significantly greater school failure than other students. Specifically, these students exhibited significantly less academically engaged time in academic settings, initiated and were involved in significantly more negative interactions with peers, had

\section{FOCuson Exceptional children}

ISSN 0015-511X FOCUS ON EXCEPTIONAL CHILDREN (USPS 203-360) is published monthly except June, July, and August as a service to teachers, special educators, curriculum specialists, administrators, and those concerned with the special education of exceptional children. This publication is annotated and indexed by the ERIC Clearinghouse on Handicapped and Gifted Children for publication in the monthly Current Index to Journals in Education (CIJE) and the quarterly index, Exceptional Children Education Resources (ECER). The full text of Focus on Exceptional Children is also available in the electronic versions of the Education Index. It is also available in microfilm from Xerox University Microfilms, Ann Arbor, MI. Subscription rates: Individual, $\$ 30$ per year; institutions, $\$ 40$ per year. Copyright (C) 1995, Love Publishing Company. All rights reserved. Reproduction in whole or part without written permission is prohibited. Printed in the United States of America. Second class postage is paid at Denver, Colorado. POSTMASTER: Send address changes to:

Love Publishing Company

Executive and Editorial Office

1777 South Bellaire Street

Denver, Colorado 80222

Telephone (303) 757-2579
Edward L. Meyen

University of Kansas

University of Kansas Medical Center
Richard J. Whelan

$$
\text { Publisher }
$$$$
\text { Publisher }
$$

Holly T. Rumpler Senior Editor more school discipline contacts, were perceived by teachers as less socially skilled, and experienced lower school attendance than their peers.

Walker et al. (1987; 1995) suggested that students who continue to exhibit antisocial behaviors over time will be at increased risk not only for continued school failure but also for membership in deviant peer groups, school dropout, and eventual delinquency and adult criminal careers. They concluded that "the long-term developmental implications for children who display this behavior pattern are extremely serious" (Walker et al., 1987, p. 15). Walker and his colleagues (Bullis \& Walker, in press; Walker et al., 1995) provided evidence that if antisocial behavior patterns are not identified and treated before children reach the age of eight, these patterns are considered to be chronic and are much more difficult to ameliorate than when they are identified and treated before that time. In fact, antisocial behaviors that are present in childhood have been found to be remarkably durable over time. In her classic follow-up study of children exhibiting deviant behavior, Robins (1966) found that childhood antisocial status was the most powerful predictor of adjustment problems in adults.

The focus of this article is on the spectrum of behaviors judged by others as aggressive or violent. Students who exhibit these patterns may or may not be assigned formal diagnostic labels such as conduct disorder, oppositional defiant disorder, or emotional and behavioral disorder. Antisocial behavior patterns, assessment methodologies, and intervention strategies are described.

\section{AGGRESSION AND VIOLENCE}

Aggressive and violent tendencies are the defining characteristics of most students who have been identified as antisocial. Overt forms of antisocial behavior are characterized by aggressive acts directed against persons and include verbal or physical assault, oppositional-defiant behavior, use of coercive tactics, and humiliation of others (Walker, 1993). From a social learning perspective, aggression is defined as gestural, verbal, and physical behaviors that result in physical, material, or psychological pain or injury to another person. Younger aggressive students demonstrate higher rates of such behaviors as humiliating, biting, being destructive, whining, yelling, teasing, being noncompliant, and being negative than their nonaggressive peers (Patterson, Ray, Shaw, \& Cobb, 1969). A defining characteristic of older aggressive students is the persistence of these behaviors over time. Although most children demonstrate a significant 
decrease in aggressive behavior as they mature, aggressive children maintain a consistently high rate of aggressiveness as they grow older.

The student's social environment greatly influences the level and intensity of his or her aggressive and violent behaviors in the school and classroom. Social learning may be the most important determinant of both aggressive and prosocial behavior. According to Bandura (1973) aggression is learned through the observation of aggression and its consequences and through experiencing the direct consequences of aggressive and nonaggressive behaviors. Kauffman (1993) made the following generalizations about the effects of social learning on aggression and violence:

- Children learn many aggressive responses by observing models or examples.

- Children are more likely to imitate aggressive models when the models are of high social status and when they observe the models receiving reinforcement or not receiving punishment for aggression.

- Children learn aggression when their aggressive acts do not lead to aversive consequences or succeed in obtaining reinforcement by harming others.

- Aggression is more likely to occur when children are aversively stimulated by physical assault or verbal threats, taunts, or insults; by thwarting goal-directed behavior; or by decreased positive reinforcement.

- Three types of reinforcement may maintain aggressive behavior: external reinforcement (tangible rewards or increased social status for aggression, removal of aversive conditions, victim pain or suffering); vicarious reinforcement (gratification from observing others rewarded for aggression); and self-reinforcement (selfreward following successful aggression).

- Aggression may be perpetuated by cognitive processes and rationales that justify hostile behavior.

- The punishment of children by adults may result in aggression when it causes pain, when there are no positive alternatives to the punished behavior, when punishment is delayed or inconsistent, or when punishment provides a model of aggressive behavior. (p. 321)

Kerr and Nelson (1989) suggested three functional explanations for aggression in the classroom. First, the aggressive behavior may be under inappropriate stimulus control. Whereas certain forms of hurtful behavior may be deemed appropriate under specific conditions (e.g., self-defense, with mutual consent, for the protection of others), the students who are antisocial may exhibit these behaviors in situ- ations that do not warrant aggression. In addition, such students may lack the ability to discriminate the environmental cues or prompts that set the occasion for prosocial rather than antisocial behaviors. Second, aggressive behaviors often are reinforced by tangible reward or personal gain, by the reaction of others, or by the avoidance of aversive, undesired, or unpleasant situations or consequences. Third, aggressive behavior may be imitated. If the student who is antisocial is a member of a group that places value on aggression and toughness, he or she may imitate the aggressive behavior exhibited by peers or other high-status models.

Thus, from a social learning perspective, student aggression may occur as a result of a complex interaction of any of the following three factors: inappropriate or ineffective stimulus control, direct or indirect reinforcement of aggression, and modeling of aggression. To develop and implement effective intervention strategies to ameliorate antisocial behaviors, and to identify and teach prosocial skills in lieu of aggressive and violent acts, it is important to conduct functional assessments of aggressive behavior across classroom and school contexts. Assessment is accomplished through a functional analysis of the antecedents and consequences of both antisocial and prosocial behaviors.

\section{ASSESSMENT OF AGGRESSIVE BEHAVIOR}

The most successful strategies for managing aggressive behavior are based on early identification and intervention. Children who are likely to develop chronic patterns of aggressive behavior are identifiable at an early age. Because the roots of chronic aggression are in early socialization experiences, behavior patterns leading to this condition often are evident before children enter school (Kazdin, 1987). In fact, two stable patterns of behavioral disorders emerge during the preschool years: internalizing or withdrawing and externalizing or acting out (Achenbach \& McConaughy, 1987; Walker \& Bullis, 1991). Externalizing behavior patterns are more prevalent and may involve or lead to aggression, noncompliance, and delinquency.

\section{Systematic Schoolwide Screening}

Systematic screening procedures have been developed that reliably identify students who are at risk for the development of aggressive behavior patterns (McConaughy \& Achenbach, 1989). One of these procedures, developed by Walker and Severson, is called Systematic Screening for Behavior Disorders (SSBD). This multiple gating procedure 
begins with the classroom teacher nominating up to 10 students who are at risk for externalizing behavior disorders and then rank-ordering them according to their degree of acting-out behavior. The same procedure is used for screening pupils at risk for internalizing behavior disorders. However, because the focus of this article is on externalizing behavior, screening for internalizing disorders will not be described. The second gate involves the teacher completing two brief rating scales for the three highest-ranked pupils. Those students who exceed local norms are advanced to the next gate, in which trained observers make two sets of controlled, 15-minute observations of the students in structured academic activities and unstructured play activities. Students who exceed age- and sex-appropriate norms may be assessed through standardized diagnostic procedures and may receive early intervention services. The SSBD procedure offers the advantage of exposing all students to systematic screening (Walker et al., 1988).

In terms of intervention, the great advantage of systematic screening programs is that they identify aggressive and violent behavior problems early on, at a time when these problems are most responsive to intervention efforts. As mentioned earlier, abundant research supports Bullis and Walker's (in press) contention that antisocial behavior, if not addressed by the time children reach the age of eight, is extremely durable and resistant to treatment.

\section{Assessment Methodology}

Significant advances in behavioral assessment procedures have been made in recent years. The technology includes the careful study of both behavior and the contexts in which it occurs. The strategy of behavioral-ecological assessment, for example, involves the evaluation of observable student behaviors over the range of environmental settings in which they occur (Kerr \& Nelson, 1989). The goals are to (a) identify the specific interpersonal and environmental variables within each setting that influence behavior; (b) analyze the behavioral expectations for various settings; and (c) compare those expectations with the student's behavior across the settings (Polsgrove, 1987). This strategy has yielded a rich supply of information about the environmental factors that influence aggressive behavior as well as the functions that such behavior serves for the student.

Wehby (1994) identified four hypotheses about the factors that lead to aggressive behavior that have emerged from the available research. Aggressive behavior may be the result of (a) a social skills deficit; (b) positive or negative reinforcement; (c) environmental deficits; or (d) deficits in the cognitive processing of social stimuli. Although these hypotheses overlap and are not inclusive of all the possible causes of aggressive behavior, each has been supported by research. For example, some children engage in aggressive behavior because they lack the appropriate social skills to gain entry into peer activities and to negotiate conflicts. Aggressive behavior also may be supported by attention from others or by access to desired materials or activities (positive reinforcement) as well as by escape from or avoidance of undesired activities, such as difficult tasks (negative reinforcement). The environmental-deficit hypothesis is supported by research demonstrating that aggressive children are more likely to display higher rates of aggression in settings characterized by low densities of positive reinforcement for desired behaviors or by low levels of structure.

Finally, research by Dodge and his colleagues (Dodge \& Coie, 1987; Dodge, Petit, McClaskey, \& Brown, 1986; Dodge \& Tomlin, 1987) has revealed that some aggressive children attend to irrelevant cues, fail to encode relevant information, misinterpret the intentions of others, make hostile attributions of intent, and are unable to develop competent solutions to problems.

These findings suggest that both the context and function of aggressive behavior must be considered when developing interventions. Too often, the only interventions used with aggressive behavior involve punishment tactics, which do not address the function the behavior may serve for the student. A thorough behavioral analysis of aggression should address its antecedents and consequences as well as the behavior itself.

\section{Antecedents of Aggression}

Typically, assessments of aggression have focused on the immediate antecedent events. Although such antecedents often are important factors in provoking aggression, Conroy and Fox (1994) have noted that more complex events or combinations of events, known as setting events, may be what sets the occasion for the display of aggression. These events may occur within the same setting as, and immediately precede, the aggressive behavior (e.g., a noisy, crowded room) or they may be temporally more remote (e.g., events occurring in the home before school). By noting the nature of the aggressive behavior, its time of occurrence, the other persons present, and the activities taking place, the interventionist can identify potential relationships between setting events and behavior. Conroy and Fox also recommended that interviews be conducted with persons who know the student and are familiar with his or her behavior and suggested 
the use of behavioral checklists and rating scales as alternatives to direct observation for identifying setting events. Again, knowledge of these antecedent variables may be important in designing effective interventions.

\section{Topography of Aggressive Behavior}

The topography, or form, of aggressive behavior may range from verbal taunts or insults to physical attacks on other persons or property (Kerr \& Nelson, 1989). It is important to assess and document the topographies of aggression displayed by the student as well as the sequence of behaviors leading to an aggressive act. For example, a child may exhibit a pattern of displaying agitation and then noncompliance before engaging in verbal or physical aggression. If such a pattern can be identified, it is possible to intervene early in the sequence before it has reached the point at which the environment will be severely disrupted or persons are in physical danger. Early intervention in a chain of behaviors leading to aggression is more likely to be effective than waiting until the behavior has escalated to the point at which the student has lost all control.

\section{Consequences of Aggression}

The communicative function of behavior has been studied by a number of researchers. Carr, Durand, and their colleagues initiated a line of applied behavior analytic research examining the communicative function of the behavior of persons with severe and profound disabilities (Carr \& Durand, 1985; Carr, Newsome, \& Binkoff, 1980; Durand \& Carr, 1987). This research is based on the limited verbal abilities of such individuals, which creates a need to understand the communicative purposes served by aberrant behavior. Donnellan, Mirenda, Mesaros, and Fassbender (1984) identified three categories of behaviors that serve communicative functions: (a) behaviors that express requests for attention, interactions, or items; (b) behaviors that express protests, refusals, or the desire to terminate an activity; and (c) behaviors that express declarations or comments or have personal meaning. Dunlap and his colleagues (Dunlap et al., 1993; Foster-Johnson \& Dunlap, 1993) focused on two major categories: behaviors that produce a desired event and behaviors that serve to escape or avoid an undesired event. By systematically observing the rate of undesired behaviors under different task and reinforcement conditions, researchers can test hypotheses regarding the functions these behaviors serve. Through the teaching of desired behaviors that serve the same communicative function, it has been possible to reduce the rates of undesired behaviors.
Dunlap and his colleagues have extended this research strategy to the communicative function of the behaviors of students with emotional and behavioral, but not cognitive, disabilities (Dunlap, Kern-Dunlap, Clarke, \& Robbins, 1991; Dunlap et al., 1993). This research holds great promise for the design of more effective interventions for students exhibiting aggressive and violent behavior, because it offers a proactive alternative to waiting until the aggressive behavior occurs and then punishing it.

When Shores and his colleagues (Gunter, Denny, Jack, Shores, \& Nelson, 1993; Shores, Gunter, \& Jack, 1993; Shores et al., 1993) examined the interactions between students with emotional and behavioral disabilities and their teachers, they found low rates of teacher reinforcement of desired student behavior, high rates of aversive interactions, and higher probabilities of teacher avoidance and escape behavior in the presence of pupils with aggressive behavior patterns. Their body of research compellingly demonstrates that aggressive and other undesired student behaviors may be strengthened because they produce desired outcomes or reduce the likelihood of undesired outcomes.

\section{Tools for the Functional Analysis of Aggressive Behavior}

Behavior analysts traditionally have advocated an assessment model that examines the immediate antecedents and consequences of behavior (Kerr \& Nelson, 1989). The value of such an analysis is indisputable, but the model requires full attention to the student during the observation periodsomething that is difficult for teachers to accomplish. Alternate strategies that are often more practical for busy practitioners include behavioral interviews (Gross, 1984), ratings that estimate the strength of behaviors across time and activities (Touchette, MacDonald, \& Langer, 1985), and afterthe-fact behavior incident logs (Kerr \& Nelson, 1989). Data collected from all of these strategies are useful for intervention planning.

\section{Relationship of Assessment to Intervention}

As indicated earlier, a comprehensive behavioral-ecological assessment can be used to identify the variables that are functionally related to the targeted behavior and the standards and expectations of the settings in which the behavior occurs. With this information, augmented by data indicating specific conditions affecting the rate of behavior, interventionists can design strategies tailored to the unique characteristics of the student, the behavior, and the settings in which it occurs. In particular, by analyzing the setting events 
and stimuli preceding an episode of student aggression, interventionists can become more sensitive to these variables and apply more appropriate treatments. If these strategies include teaching the student to recognize his or her indicators of agitation, to understand the communicative purpose of the behavior, and to employ more adaptive means of achieving the function served by the maladaptive behavior, the needs of the pupil and others in the setting will be better served.

\section{Monitoring the Effectiveness of Interventions}

Practitioners often object to collecting data on targeted student behaviors because such activities add to the burden of their already busy schedules. However, as White (1986, p. 522) indicated, "To be responsive to the pupil's needs the teacher must be a student of the pupil's behavior, carefully analyzing how that behavior changes from day to day and adjusting the instructional plan as necessary to facilitate continued learning." Although White was referring to students in general, the statement also pertains to students with serious behavior problems, such as aggression and violence. Whether the intervention involves reducing the frequency or intensity of aggressive acts, increasing alternatives to aggressive behavior, or both, it is important to monitor the student's (and the teacher's) progress toward the desired behavioral goals and objectives. Failure to do so involves the risk of prolonging an ineffective intervention or of continuing an intervention strategy that no longer is necessary. Formative evaluation of intervention strategies against objective data decision rules is required practice.

\section{INTERVENTION STRATEGIES}

\section{Teacher-Mediated Interventions}

Two primary types of intervention enable teachers to manage aggressive behaviors: rearranging behavior enhancement and behavior reduction contingencies for aggression and teaching appropriate, prosocial skills that are incompatible with antisocial acts. These two approaches are based on a social learning theory model that presumes that aggressive behaviors are learned and that prosocial skills that are incompatible with aggressive behaviors can be taught (Bandura, 1971).

Behavioral interventions derived from applied behavior analysis (Baer, Wolf, \& Risley, 1968, 1987) and social learning theory emphasize the use of overt, objectively observ- able behaviors as dependent measures. Such behavioral interventions may be represented on two continua: one depicting behavior enhancement procedures and one depicting behavior reduction procedures (Nelson \& Rutherford, 1988).

\section{Behavior Enhancement Contingencies}

Six levels, or types, of behavior enhancement procedures have been documented in the applied behavior analysis literature. When combined with behavior reduction procedures, these strategies have proven to be effective tools for ameliorating aggressive and violent behavior in the classroom and school. The six levels are tangible reinforcement, activity reinforcement, token reinforcement, behavioral or contingency contracting, modeling, and social reinforcement.

Tangible reinforcement. Tangible reinforcers are material items that have reinforcing value for particular students. Although they frequently are used as backup reinforcers in token economies (as described later), they also may be delivered immediately following desired student behavior. In their study of tangible reinforcement, Dewhurst and Cautela (1980) found that 5- to 12-year-old students with behavior problems rated stickers as their most preferred reinforcers. Rhode, Jenson, and Reavis (1993) suggested that tangibles tend to be more effective with younger students who may not initially respond consistently to teachers' social reinforcement.

Activity reinforcement. The opportunity to engage in desired or high-probability behaviors (Premack, 1959) has been shown to be an effective reinforcement procedure with students exhibiting mild to moderate behavioral problems in school. For example, Jackson, Salzberg, Pacholl, and Dorsey (1981) effectively reduced the aggressive school-busriding behaviors of a 10 -year-old boy by making afternoon privileges at home (watching TV and playing outside) contingent upon successively (progressively) lower rates of occurrence of targeted behaviors on the bus that included yelling, name-calling, moving from seat, grabbing and throwing objects, spitting, hitting, pinching, and pushing.

Token reinforcement. Token economies have been used effectively with a wide range of student populations and agegroups and in numerous educational and treatment settings (Kazdin, 1982). For example, Deitz, Slack, Schwarzmueller, Wilander, Weatherly, and Hilliard (1978) demonstrated the positive effects of a token system in which a seven-year-old student received stars exchangeable for time on the playground for every 2-minute period in which she exhibited one or zero aggressive behaviors, including shov- 
ing, pushing, hitting, throwing objects, and destroying objects. Tokens can be exchanged for a variety of tangible and activity reinforcers, and they often can be delivered more quickly and easily than tangible reinforcers.

Behavioral or contingency contracting. Behavioral contracting involves the negotiation and implementation of a formal written agreement between a student and a teacher, parent, peer, or other person. A typical contract specifies the behavior(s) to be increased or decreased, the student goals with respect to the behaviors, and the consequences associated with goal attainment or nonattainment (Rutherford, 1975). Contracting has been effective in modifying a variety of desired and undesired behaviors in students of all ages. Rutherford and Polsgrove (1981), who reviewed 35 studies in which contracts were made with children and youth who exhibited behaviorally disordered, antisocial, or delinquent behavior concluded that "contracting has contributed to behavioral change in a number of instances" (p. 64).

Modeling. With this behavior enhancement procedure, students observe adult or peer models performing and being reinforced for demonstrating prosocial behaviors and strategies. When students then imitate these modeled behaviors, they are reinforced as well. Modeling has the potential for reinforcement at two stages-at the point of observing the model being reinforced (vicarious reinforcement) and at the point when the student performs the same behaviors.

Modeling has been used mainly for teaching complex prosocial behaviors and typically is implemented in conjunction with other behavior enhancement and reduction procedures, such as behavior rehearsal and role-playing interventions. Modeling is an important component of Goldstein's (1987) program for teaching prosocial skills to adolescents who exhibit antisocial behavior. Through the use of live acting by trainers or of audiovisual modeling displays, models demonstrate the skill steps necessary to expertly perform such aggression-relevant prosocial skills as responding to failure, responding to anger, dealing with being left out, dealing with an accusation, and dealing with group pressure.

Social reinforcement. Social reinforcement consists of the teacher giving positive verbal and physical feedback, attention, and approval for desired student behavior. When used in combination with other behavior enhancement and reduction procedures, this type of intervention often is effective for developing the prosocial behaviors of students who behave antisocially (Rutherford, Chipman, DiGangi, \& Anderson, 1992). Walker et al. (1995) pointed out that behav- ior-specific adult praise is an extremely powerful form of focused attention that communicates approval and positive regard. They noted that although students who behave antisocially initially may not be responsive to adult praise because of a history of negative adult interactions, social reinforcement paired with other behavior enhancement procedures eventually will increase the positive valence of praise.

\section{Behavioral Reduction Contingencies}

Because the antisocial aggressive behavior patterns of children and youth often are so well developed, aversive, and resistant to behavior enhancement procedures used in isolation, interventions are most effective when they combine behavior enhancement and reduction techniques (Nelson \& Rutherford, 1988; Walker et al., 1995). A substantial body of research has identified several behavior reduction procedures, including differential reinforcement, response cost, and time-out.

Differential reinforcement. Four strategies have been developed for reducing undesired behaviors through differential reinforcement. Differential reinforcement of incompatible behavior (DRI) and differential reinforcement of alternate behavior (DRA) involve, as their names imply, reinforcing behaviors that are incompatible with or merely alternatives to problem behaviors. Differential reinforcement of low rates of behavior (DRL) involves providing reinforcement when problem behavior occurs less than a specified amount in a period of time. Differential reinforcement of the omission of behavior (DRO) requires that the problem behavior be suppressed for an entire interval of time (Deitz \& Repp, 1983).

DRI and DRA have been effective with a variety of student populations and problem situations when the behaviors that are incompatible with or alternative to aggression, for example, prosocial skills and strategies for social interaction, have been systematically reinforced. DRL has been used primarily to reduce minor classroom misbehaviors or to eliminate in a stepwise process the limited number of aggressive responses that may be initially tolerated. Using DRL procedures, Deitz et al. (1978) reduced to nearly zero the number of antisocial and other inappropriate behaviors exhibited by a seven-year-old boy in a special class. Epstein, Repp, and Cullinan (1978) and Trice and Parker (1983) successfully used DRL to reduce the obscene and aggressive verbal responses of six behaviorally disordered 6- to 9-yearolds and two disruptive 16-year-olds, respectively. DRO has been used successfully to reduce the occurrence of a number of severe behavior problems, although it usually is employed in combination with other behavior enhancement 
and reduction procedures (Stainback, Stainback, \& Dedrick, 1979). Rose (1979), Rapoff, Altman, and Christopherson (1980), and Dorsey, Iwata, Ong, and McSween (1980) successfully used DRO alone or in combination with other behavior reduction techniques to significantly reduce self-aggressive and self-injurious behaviors of students with severe disabilities.

Response cost. Research involving the removal of reinforcers following the occurrence of undesired target behaviors has indicated that this strategy is a powerful, cost-effective procedure for preventing and suppressing the occurrence of a variety of aggressive and violent behaviors (Walker, 1983). The two most common applications of response cost involve removal of the opportunity to participate in specified activities and token removal, for example, the imposition of fines within token economy systems following inappropriate behavior (Rutherford, 1983). Walker et al. (1995) suggested that response cost contingencies usually are necessary, in combination with other interventions, to produce socially valid reductions in aggressive and violent antisocial behaviors. The research literature supports the combined application of limit setting, reinforcement contingencies, and aversive consequences, such as time-out and response cost. Examples of response cost contingencies with students with behavior problems include a group contingency of 1minute reductions in a special 10 -minute recess for each instance of a "naughty finger" (raised fist with middle finger extended), a verbal reference to it, or "tattling" about another child's use of the naughty finger (Sulzbacher \& Houser, 1968); a response cost lottery in which adolescent students begin the day with a fixed number of reward tickets, lose tickets contingent upon misbehavior, and exchange remaining tickets for rewards (Proctor \& Morgan, 1991); and token loss contingent upon the aggressive behaviors of predelinquent boys (Phillips, 1968).

Time-out. Response contingent time-out, or time-out from positive reinforcement, is a behavior reduction procedure whereby access to the sources of reinforcement is removed for a period of time following the occurrence of maladaptive or antisocial behaviors (Rutherford \& Nelson, 1983). This complex intervention may be implemented at several different levels, ranging from planned ignoring to seclusion (Nelson \& Rutherford, 1983). Research has shown time-out to be effective with children with moderate to severe behavior problems, but many factors appear to influence its success, including the level of time-out used, how it is applied, the schedule under which it is administered, procedures for removing the student from time-out, and the concurrent use of other behavior enhancement and reduction interventions (Gast \& Nelson, 1977; Rutherford \& Nelson, 1983).

Substantial empirical evidence supports the use of planned ignoring time-out plus social reinforcement for reducing the aggressive behaviors of young children (Pinkston, Reese, LeBlanc, \& Bayer, 1973; Sibley, Abbott, \& Cooper, 1969; Wasik, Senn, Welch, \& Cooper, 1969). Also proven successful for young children exhibiting aggressive behavior have been planned ignoring and restraint plus social reinforcement (Noll \& Simpson, 1979); contingent observation time-out plus social reinforcement (Porterfield, HerbertJackson, \& Risley, 1976); reduction of response maintenance stimuli time-out plus group free time (Devine \& Tomlinson, 1976); exclusion time-out plus social reinforcement (Firestone, 1976; Mace \& Heller, 1990), and seclusion time-out plus social reinforcement (Sachs, 1973; Sloane, Johnstone, \& Bijou, 1967; Webster, 1976).

\section{Extinction, Verbal Aversives, Physical Aversives, and Overcorrection.}

Four behavior reduction contingencies that generally have not proven to be effective in reducing antisocial behavior patterns are extinction, verbal aversives, physical aversives, and overcorrection.

Extinction. Although withholding reinforcers (e.g., attention) that are thought to be maintaining undesired behavior following the occurrence of that behavior has proven to be a successful strategy with a variety of behaviors and students (Polsgrove \& Reith, 1983), Stainback et al. (1979) concluded that extinction is one of the least effective procedures for controlling severe maladaptive behavior. Further, they stated that it is an inappropriate strategy for reducing behaviors reinforced by consequences other than those controlled by the teacher (e.g., severe aggressive and disruptive behaviors).

Verbal aversives. Verbal reprimands have proven effective for reducing mild and moderate behavior problems (Nelson, 1981; Rutherford, 1983), but, unless used with other strategies, they are not likely to be effective in reducing more serious forms of maladaptive behaviors. However, when verbal reprimands are associated with other punishing consequences, such as response cost or time-out, they may acquire aversive properties and subsequently be effective when used alone (Gelfand \& Hartman, 1984).

Physical aversives. Substances with aversive tastes and odors, electric shock, and slaps, pinches, and spankings 
constitute the range of physical aversive procedures that have been investigated as ways to reduce problem behaviors. In general, these forms of punishment have been found to be efficient and effective means of weakening severe maladaptive behaviors, such as self-injurious and extreme assaultive behaviors of individuals with severe disabilities in institutional settings (Rutherford, 1983; Stainback et al., 1979). However, because parents and community groups frequently object to the use of such extreme interventions, alternate procedures are required in public school settings.

In addition, physical aversives may not be effective for reducing students' serious aggressive and violent antisocial behavior when that behavior is rooted in physical abuse and violence. For such students, aggression may be a response learned through modeling of the physically punitive behaviors of adults. To use physical aggression to control aggression is paradoxical and, as noted by Rose (1983), not empirically validated. Physical aversives, in the form of corporal punishment have failed to produce sustained suppression of inappropriate behaviors (Rose, 1981), increase the likelihood that the student will behave aggressively in other settings (Maurer, 1974), and make no contribution to the development of new, appropriate behaviors (Goldstein, Apter, \& Harootunian, 1984).

Overcorrection. This complex procedure involves components of restraint and guided practice, social punishment, extinction, and time-out. Both restitutional and positive practice overcorrection have been effective in reducing a wide variety of self-stimulatory and self-injurious behaviors (Stainback et al., 1979), as well as the behavior problems of students with mild disabilities (Nelson, 1981). In addition, restitutional overcorrection has been effective in reducing aggressive behavior (Gelfand \& Hartman, 1984). However, claims that overcorrection is superior to other techniques for reducing aggressive behavior have not been substantiated. Further, the unacceptability of overcorrection to many practitioners, and student resistance to overcorrection procedures are obstacles to its effectiveness (Axelrod, Brantner, \& Meddock, 1978).

\section{Teaching Alternative Behaviors}

This component of teacher-mediated intervention involves teaching alternative prosocial skills and anger-control strategies to replace aggressive and violent behaviors in the classroom and school. The contingency management procedures reviewed earlier will help manage the outbursts of an aggressive student but may fall short of offering the student new and better ways to solve problems with others.
Behavior enhancement and reduction procedures can be used, however, to both manage aggression and violence and teach replacement responses. Through the functional assessment procedures described earlier in this article, practitioners can formulate hypotheses regarding what purposes the undesired behavior serves the student and can then identify and teach the student an alternative, prosocial response. Naturally, it is important to provide systematic positive reinforcement of prosocial skills, especially when they are first acquired. Two primary intervention approaches have been designed for teaching alternative behaviors to student aggression: social skills training and anger management training.

Social skills training. The basic goal of social skills training is to help the student who behaves antisocially acquire the social skills needed to avoid interpersonal rejection and gain acceptance by significant peers and adults. Aggressive students often are at a serious disadvantage with regard to both peer and teacher social interactions because of their deficits in the areas of social perception and social skills. Walker et al. (1995) pointed out that peer and teacher rejection is nearly an inevitable consequence of displaying antisocial behavior in school.

Walker et al. (1995) defined social skills for students as a set of competencies that allow students to initiate and maintain positive social relationships with others, contribute to positive peer acceptance and satisfactory school adjustment, and cope effectively and adaptively with the larger social environment. Social competence is a judgment-based evaluation of the student by peers, teachers, parents, and other adults showing recognition that the student exhibits persistent and generalized social skills and strategies across multiple settings and with multiple individuals.

A number of social skills training programs have been developed to promote the social competence of aggressive and socially deficient children and youth. Four of these programs are Goldstein's Structured Learning curriculum (Goldstein, 1987; Goldstein, Sprafkin, Gershaw, \& Klein, 1980; McGinnis \& Goldstein, 1984); The Boys' Town Teaching Social Skills to Youth curriculum (Dowd \& Tierney, 1992); The Walker Social Skills curriculum (Walker, Todis, Holmes, \& Horton, 1988); and the Teaching Social Skills: A Practical Instructional Approach curriculum (Rutherford et al., 1992).

All social skills curricula offer a similar format. The Teaching Social Skills: A Practical Instructional Approach curriculum, which focuses on teaching prosocial skills to elementary-aged students who are aggressive, immature, or 
withdrawn, can serve as an illustration. Each of its interventions follows a standard format that incorporates effective components of behavioral intervention. In each case, the student is taught to eventually self-manage prosocial behaviors and effective and positive social interactions. Although the interventions are teacher-directed at first, they are structured to ensure that control is placed eventually with the student. The student is provided with the tools to evaluate the environment, consider the alternatives, choose prosocial behaviors or strategies, monitor the effects of those behaviors, and adjust his or her behavior accordingly.

The five components of the Teaching Social Skills program include:

1. Teach the student to identify alternative prosocial behaviors and strategies.

2. Provide the student with models demonstrating prosocial behaviors and strategies.

3. Provide the student with opportunities to practice prosocial behaviors and strategies in nonthreatening role-play and real-life situations.

4. Socially reinforce the student in a direct manner for demonstrating prosocial behaviors and strategies.

5. Teach the student how to self-control the continued use of prosocial skills and strategies through self-monitoring, self-evaluation, and self-reinforcement (Rutherford et al., 1992).

Anger management training. Although the teacher-mediated contingency management approaches identified earlier may help manage and control aggressive and violent behavior effectively in the school, students who behave antisocially often continue to be persistently angry in out-ofschool interactions with both peers and adults. Feindler and Ecton (1986) emphasized the following impediments to successfully implementing contingency management interventions with these students: (a) competing peer reinforcement contingencies; (b) lack of powerful competing reinforcers; (c) low-frequency or covert aggressive behaviors that go undetected or unconsequented; (d) inconsistent behavior change agents; and (e) lack of maintenance and generalization of treatment effects.

An important addition to teacher-mediated contingency management interventions that target antisocial behavior is the direct treatment of high anger arousal, which may accompany impulsive and explosive behavior. As Feindler and Ecton (1986) pointed out, although aggressive behavior is not always accompanied by anger arousal, most theorists agree that a state of anger often is an antecedent to aggres- sive behavior. Therefore, despite the difficulties in operationalizing or measuring a hypothetical construct such as anger, a primary focus of the treatment of aggression should be on anger control.

Anger control programs that have been developed for aggressive and violent children and adolescents include stress inoculation training (Maag, Parks, \& Rutherford, 1988; Meichenbaum, 1985); the "Think-Aloud" cognitive-behavioral approach (Camp, Blum, Hebert, \& van Doornick, 1977); Adolescent Anger Control (Feindler \& Ecton, 1986); Anger Management for Youth (Eggert, 1994); and Aggression Replacement Training (Goldstein \& Glick, 1987).

Aggression replacement training combines the contingency management procedures and prosocial skills development of Goldstein's Structured Learning curriculum (Goldstein, 1987) with cognitive-behavioral anger control training strategies and interventions (Finch, Moss, \& Nelson, 1993). Anger control training teaches antisocial behavior inhibition - that is, the reduction, management, or control of anger and aggression. Students are taught to respond to provocations that previously resulted in anger with a chain of responses consisting of the following:

1. Triggers-identifying internal and external events that stimulate anger.

2. Cues-identifying physiological factors that signal anger arousal.

3. Reminders-generating anger-reducing self-statements.

4. Reducers-using techniques such as backward counting, deep breathing, peaceful imagery, and reflection on longterm consequences.

5. Using prosocial skill alternatives to anger and aggression.

6. Conducting self-evaluations of the use and results of the anger control sequence (Goldstein \& Glick, 1987).

\section{Schoolwide Interventions}

Aggression and violence are becoming increasingly prevalent in individual students and groups of students in U. S. schools (Goldstein, Harootunian, \& Conoley, 1994). Although these antisocial behaviors often are serious, persistent, and well entrenched in students' patterns of social interaction with peers, teachers, and other adults, strong empirical evidence indicates that the teacher-mediated interventions reviewed in this article can have a significant impact on ameliorating these behaviors in the context of a schoolwide intervention plan. Research by Walker et al. (1995), Simpson, Miles, Walker, Ormsbee, and Downing (1991), and Sprick, Sprick, and Garrison (1993) presents a 
strong case for proactive rather than reactive schoolwide programming that targets aggressive and violent behavior.

Walker et al. (1995) described procedures for developing a proactive schoolwide discipline program whereby school staff collaborate to design and implement an instructional plan for teaching expected prosocial behaviors to and correcting the inappropriate behaviors of students who behave antisocially. They described a system for implementing a continuum of preestablished rules and consequences for managing minor rule infractions, serious school violations, and illegal behavior. In addition, they described procedures for providing individual assistance to students who do not respond to teacher-mediated or general schoolwide interventions. The keys to the success of schoolwide procedures that effectively deal with aggression and violence are that they are proactive rather than reactive in their approach to discipline and that they involve the entire school staff in the design and implementation of the discipline plan.

Sprick et al. (1993) and Simpson et al. (1991) emphasized the collaborative aspect of developing plans for schoolwide intervention for antisocial behavior. Sprick et al. suggested that a schoolwide plan is most effective when school personnel organize to develop collaborative interventions for students. Simpson et al. recommended the development of transdisciplinary programming for dealing with aggressive and violent behavior in the schools. Unlike the traditional "pull-out" model in which professionals work with students on isolated skills and provide segregated instruction, transdisciplinary educational and treatment programs are structured so that multiple interventions can occur simultaneously. Professionals operating within such transdisciplinary programs work together to determine students' needs and to evaluate progress within and between programs.

\section{CONCLUSIONS}

Abundant technology exists for assessing and successfully intervening with aggressive and violent behavior in the schools. In most cases, the behavior patterns that lead to chronic aggression are evident before children enter school. Systematic screening procedures that effectively identify students at risk for aggressive and violent behavior are available and should be used on a schoolwide basis as part of a system of early intervention.

Recent studies of aggression have led to the development of strategies for identifying the functional relationships between patterns of aggressive behavior and the environmen- tal antecedents and consequences of that behavior. Identification of these functional relationships is essential to the design of interventions that not only are effective but also are least intrusive and proactive. A student's aggressive behavior may serve either of two purposes: to gain something the student wants or to escape something that the student does not want (Foster-Johnson \& Dunlap, 1993). By understanding the function of the behavior for the student, practitioners can design proactive interventions, such as modifying a curriculum that is too difficult or teaching prosocial skills to replace undesired behavior the student uses to fulfill his or her wants.

Proactive interventions, in which new skills are taught systematically, offer an advantage over reactive strategies (e.g., punishment) because the instructional interventions are not dependent upon the occurrence of the undesired behavior. Because the undesired behavior is likely to occur at low rates, proactive strategies that teach appropriate and replacement behaviors or adaptive coping skills have the further advantage of allowing instructional trials to be delivered much more frequently. Finally, proactive strategies that focus on early identification and prevention are less intrusive and more effective than interventions applied after the behavior has occurred.

It is important to carefully monitor aggressive behavior (or earlier behavior patterns that are the targets of intervention) during the systematic application of intervention strategies. Only through formative evaluation procedures can practitioners adjust and adapt interventions to improve their effectiveness.

Finally, it is important to recognize that most students with aggressive and violent patterns of behavior are aggressive out of school as well as in school. Therefore, educators should establish links to family members and community professionals to extend the analysis of the student's behavior and to allow for the design of interventions that can be applied consistently across multiple settings. Comprehensive, ecologically based intervention is critical to the successful treatment of established patterns of aggressive and violent behavior.

\section{REFERENCES}

Achenbach, T. M., \& McConaughy, S. M. (1987). Empirically based assessment of child and adolescent psychopathology. Newbury Parks, CA: Sage.

American Psychiatric Association. (1987). Diagnostic and statistical manual of mental disorders (3rd ed.). Washington DC: Author. 
Axelrod, S., Brantner, J. P., \& Meddock, T. D. (1978). Overcorrection: A review and critical analysis. Journal of Special Education, 12, 367-391.

Baer, D. M., Wolf, M. M., \& Risley, T. R. (1968). Some current dimensions of applied behavior analysis. Journal of Applied Behavior Analysis, 1, 91-97.

Baer, D. M., Wolf, M. M., \& Risley, T. R. (1987). Some still current dimensions of applied behavior analysis. Journal of Applied Behavior Analysis, 20, 313-328.

Bandura, A. (1971). Social learning theory. Morristown, NJ: General Learning.

Bandura, A. (1973). Aggression: A social learning analysis. Englewood Cliffs, NJ: Prentice Hall.

Bullis, M., \& Walker, H. M. (in press). Characteristics and causal factors of troubled youth. In C. M. Nelson, R. B. Rutherford, \& B. I. Wolford (Eds.), Developing comprehensive and collaborative systems that work for troubled youth: A national agenda. Richmond, KY: National Coalition for Juvenile Justice Services.

Camp, B. W., Blum, G., Hebert, F., \& van Doornick, W. (1977). "Think-Aloud": A program for developing self-control in aggressive young boys. Journal of Abnormal Child Psychology, 5, 152-169.

Carr, E. G., \& Durand, M. (1985). Reducing behavior problems through functional communication training. Journal of Applied Behavior Analysis, 18, 111-126.

Carr, E. G., Newsome, C. D., \& Binkoff, J. A. (1980). Escape as a factor in the aggressive behavior of two retarded children. Journal of Applied Behavior Analysis, 13, 101-117.

Conroy, M. A., \& Fox, J. J. (1994). Setting events and challenging behaviors in the classroom: Incorporating contextual factors into effective intervention plans for children with aggressive behaviors. Preventing School Failure, 38(3) 29-34.

Deitz, D. E., \& Repp, A. C. (1983). Reducing behavior through reinforcement. Exceptional Education Quarterly, 3(4), 34-46.

Deitz, S. M., Slack, D. J., Schwarzmueller, E. B., Wilander, A. P., Weatherly, T. J., \& Hilliard, G. (1978). Reducing inappropriate behavior in special classrooms by reinforcing average interresponse times: Interval DRL. Behavior Therapy, 9, 37-46.

Devine, V. T., \& Tomlinson, J. R. (1976). The "workclock": An alternative to token economies in the management of classroom behaviors. Psychology in the Schools, 13, 163-170.

Dewhurst, D. L., \& Cautela, J. R. (1980). A proposed reinforcement schedule for special needs children. Journal of Behavior Therapy and Experimental Psychiatry, 2, 109-113.

Dodge, K. A., \& Coie, J. D. (1987). Social information processing factors in reactive and proactive aggression in children's peer groups. Journal of Personality and Social Psychology, 53, 1146-1158.

Dodge, K. A., Petit, G. S., McClaskey, C. L., \& Brown, M. (1986). Social competence in children. Monographs for the Society for Research in Child Development, 51 (2, Serial No. 213).
Dodge, K. A., \& Tomlin, A. (1987). Cue utilization as a mechanism of attributional bias in aggressive children. Social Cognition, 5, 280-300.

Donnellan, A. M., Mirenda, P. L., Mesaros, R. A., \& Fassbender, L. L. (1984). Analyzing the communicative functions of aberrant behavior. Journal of the Association of the Severely Handicapped, 9, 201-212.

Dorsey, M. F., Iwata, B. A., Ong, P., \& McSween, T. E. (1980). Treatment of self-injurious behavior using a water mist: Initial response suppression and generalization. Journal of Applied Behavior Analysis, 13, 343-353.

Dowd, T., \& Tierney, J. (1992). Teaching social skills to youth: A curriculum for child-care providers. Boys Town, NE: Boys Town Press.

Dunlap, G., Kern, L., dePerczel, M., Clarke, S., Wilson, D., Childs, K. E., White, R., \& Falk, G. D. (1993). Functional analysis of classroom variables for students with emotional and behavioral disorders. Behavioral Disorders, 18, 275-291.

Dunlap, G., Kern-Dunlap, L., Clarke, S., \& Robbins, F. R. (1991). Functional assessment, curricular revision, and severe behavior problems. Journal of Applied Behavior Analysis, 24, 387-397.

Durand, V. M., \& Carr, E. G. (1987). Social influences of selfstimulatory behavior: Analysis and treatment application. Journal of Applied Behavior Analysis, 20, 119-132.

Eggert, D. L. (1994). Anger management for youth: Stemming aggression and violence. Bloomington, IN: National Educational Service.

Epstein, M. H., Repp, A. C., \& Cullinan, D. (1978). Decreasing "obscene" language of behaviorally disordered children through the use of a DRL schedule. Psychology in the Schools, 15, 419-423.

Feindler, E. L., \& Ecton, R. B. (1986). Adolescent anger control: Cognitive-behavioral techniques. New York: Pergamon.

Finch, A. J., Moss, J. H., \& Nelson, W. M. (1993). Childhood aggression: Cognitive-behavioral therapy strategies and interventions. In A. J. Finch, W. M. Nelson, \& E. S. Ott (Eds.), Cognitive-behavioral procedures with children and adolescents: a practical guide (pp. 148-205). Boston: Allyn \& Bacon.

Firestone, P. (1976). The effects and side effects of time-out on an aggressive nursery school child. Journal of Behavior Therapy and Experimental Psychiatry, 6, 7981.

Foster-Johnson, L., \& Dunlap, G. (1993). Using functional assessment to develop effective, individualized interventions for challenging behaviors. Teaching Exceptional Children, 25(3), 44-50.

Gast, D. L., \& Nelson, C. M. (1977). Time-out in the classroom: Implications for special education. Exceptional Children, 43, 461-464.

Gelfand, D. M., \& Hartman, D. P. (1984). Child behavior analysis and therapy (2nd ed.). New York: Pergamon. 
Goldstein, A. P. (1987). Teaching prosocial skills to antisocial adolescents. In C. M. Nelson, R. B. Rutherford, \& B. I. Wolford (Eds.). Special education in the criminal justice system (pp. 215-250). Columbus, OH: Merrill.

Goldstein, A. P., Apter, S. J., \& Harootunian, B. (1984). School violence. Englewood Cliffs, NJ: Prentice Hall.

Goldstein, A. P., \& Glick, B. (1987). Aggression replacement training, Champaign, IL: Research Press.

Goldstein, A. P., Harootunian, B., \& Conoley, J. C. (1994). Student aggression: Prevention, management, and replacement training. New York: Guilford.

Goldstein, A. P., Sprafkin, R. P., Gershaw, N. J., \& Klein, P. (1980). Skillstreaming the adolescent: A structural learning approach to teaching prosocial skills. Champaign, IL: Research Press.

Gross, A. M. (1984). Behavioral interviewing. In T. H. Ollendick \& M. Hersen (Eds.). Child behavioral assessment: Principles and procedures (pp. 61-79). New York: Pergamon.

Gunter, P. L., Denny, R. K., Jack, S. L., Shores, R. E., \& Nelson, C. M. (1993). Aversive stimuli in academic interactions between students with serious emotional disturbance and their teachers. Behavioral Disorders, 18, 265-274.

Horne, A. M., \& Sayger, T. V. (1990). Treating conduct and oppositional defiant disorders in children. New York: Pergamon.

Jackson, A. T., Salzberg, C. L., Pacholl, B., \& Dorsey, D. S. (1981). The comprehensive rehabilitation of a behavior problem child in his home and community. Education and Treatment of Children, 4, 195-215.

Kauffman, J. M. (1993). Characteristics of emotional and behavioral disorders of children and youth. New York: Macmillan.

Kazdin, A. E. (1982). The token economy: a decade later. Journal of Applied Behavior Analysis, 15, 431-445.

Kazdin, A. E. (1987). Conduct disorders in childhood and adolescence. Newbury Park, CA: Sage.

Kerr, M. M., \& Nelson, C. M. (1989). Strategies for managing behavior problems in the classroom (2nd ed.). Columbus, $\mathrm{OH}$ : Merrill.

Maag, J. W., Parks, B. T., \& Rutherford, R. B. (1988). Generalization and behavior covariation of aggression in children receiving stress inoculation therapy. Child and Family Behavior Therapy, 10(2/3), 29-47.

Mace, F. C., \& Heller, M. (1990). A comparison of exclusion timeout and contingent observation for reducing severe disruptive behavior in a 7-year-old boy. Child and Family Behavior Therapy, 12(1), 57-68.

Maurer, A. (1974). Corporal punishment. American Psychologist, 29, 614-626.

McConaughy, S. M., \& Achenbach, T. M. (1989). Empirically based assessment of serious emotional disturbance. Journal of School Psychology, 27, 91-117.

McGinnis, E., \& Goldstein, A. P. (1984). Skillstreaming the elementary student. Champaign, IL: Research Press.
Meichenbaum, D. (1985). Stress inoculation training. New York: Pergamon.

Nelson, C. M. (1981). Classroom management. In J. M. Kauffman \& D. P. Hallihan (Eds.). Handbook of special education (pp. 663-687). Englewood Cliffs, NJ: Prentice Hall.

Nelson, C. M., \& Rutherford, R. B. (1983). Timeout revisited: Guidelines for its use in special education. Exceptional Education Quarterly, 3(4), 56-67.

Nelson, C. M., \& Rutherford, R. B. (1988). Behavioral interventions with behaviorally disordered children. In M. C. Wang, M. C. Reynolds, \& H. J. Walberg (Eds.). Handbook of special education: Research and practice: Mildly handicapping conditions (Vol. 2, pp. 125-143). New York: Pergamon.

Nelson, C. M., \& Rutherford, R. B. (1990). Troubled youth in the public schools: Emotionally disturbed or socially maladjusted? In P. E. Leone (Ed.). Understanding troubled and troubling youth (pp. 38-60). Newbury Park, CA: Sage.

Noll, M. B., \& Simpson, R. L. (1979). The effects of physical time-out on the aggressive behaviors of a severely emotionally disturbed child in a public school setting. AAESPH Review, 4, 399-406.

Patterson, G. R., Ray, R. S., Shaw, D. A., \& Cobb, J. A. (1969) Manual for coding of family interactions. New York: Microfiche Publications.

Phillips, E. L. (1968). Achievement Place: Token reinforcement procedures in a home-style rehabilitation setting for "predelinquent" boys. Journal of Applied Behavior Analysis, 1 , 313-323.

Pinkston, E. M., Reese, N. M., LeBlanc, J. M., \& Baer, D. M. (1973). Independent control of a preschool child's aggression and peer interaction by contingent teacher attention. Journal of Applied Behavior Analysis, 6, 115-124.

Polsgrove, L. J., \& Reith, H. (1983). Procedures for reducing children's inappropriate behavior in special education settings. Exceptional Education Quarterly, 3(4), 20-33.

Polsgrove, L. J. (1987). Assessment of children's social and behavioral problems. In W. H. Berdine \& S. A. Meyer (Eds.), Assessment in special education (pp. 141-180). Boston: Little, Brown.

Porterfield, J. K., Herbert-Jackson, E., \& Risley, T. R. (1976). Contingent observation: an effective and acceptable procedure for reducing disruptive behavior of young children in a group setting. Journal of Applied Behavior Analysis, 9, $55-64$.

Premack, D. (1959). Toward empirical behavior laws: I. Positive reinforcement. Psychological Review, 66, 219-233.

Proctor, M. A., \& Morgan, D. (1991). Effectiveness of a response cost raffle procedure on the disruptive behavior of adolescents with behavior problems. School Psychology Review, 20, 97-109.

Rapoff, M. A., Altman, K., \& Christopherson, E. R. (1980). Suppression of self-injurious behavior: Determining the least re- 
strictive alternative. Journal of Mental Deficiency Research, $24,37-46$.

Rhode, G., Jenson, W. R., Reavis, H. K. (1993). The tough kid book: Practical classroom management strategies. Longmont, CO: Sopris West.

Robins, L. N. (1966). Deviant children grown up. Baltimore: Williams \& Wilkins.

Rose, T. L. (1979). Reducing self-injurious behavior by differentially reinforcing other behaviors. AAESPH Review, 4, 170-186.

Rose, T. L. (1981). The corporal punishment cycle: A behavioral analysis of the maintenance of corporal punishment in the schools. Education and Treatment of Children, 4, 157-169.

Rose, T. L. (1983). A survey of corporal punishment of mildly handicapped students. Exceptional Education Quarterly, 3(4), 9-19.

Rutherford, R. B. (1975). Establishing behavioral contracts with delinquent adolescents. Federal Probation, 34(10), 28-32.

Rutherford, R. B. (1983). Theory and research on the use of aversive procedures in the education of moderately behaviorally disordered and emotionally disturbed children and youth. In F. H. Wood \& K. C. Lakin (Eds.), Punishment and aversive stimulation in special education (pp. 41-64). Reston, VA: Council for Exceptional Children.

Rutherford, R. B., Chipman, J., DiGangi, S. A., \& Anderson, K. (1992). Teaching social skills: a practical instructional approach. Ann Arbor, MI: Exceptional Innovations.

Rutherford, R. B., \& Nelson, C. M. (1983). Analysis of the response contingent time-out literature with behaviorally disordered students in classroom settings. In R. B. Rutherford (Ed.), Severe behavior disorders of children and youth (Vol. 5, pp. 79-105). Reston, VA: Council for Children with Behavioral Disorders.

Rutherford, R. B., \& Polsgrove, L. J. (1981). Behavioral contracting with behaviorally disordered and delinquent children and youth: an analysis of the clinical and experimental literature. In R. B. Rutherford, A. G. Prieto, \& J. E. McGlothlin (Eds.), Severe behavior disorders of children and youth (Vol. 4, pp. 49-69). Reston, VA: Council for Children with Behavioral Disorders.

Sachs, D. A. (1973). The efficacy of time-out procedures in a variety of behavior problems. Journal of Behavior Therapy and Experimental Psychiatry, 4, 237-242.

Shinn, M. R., Ramsey, E., Walker, H. M., Stieber, S., \& O’Neill, R. E. (1987). Antisocial behavior in school settings: Initial differences in an at-risk and normal population. Journal of Special Education, 21, 69-84.

Shores, R. E., Gunter, P. L., Jack, S. L. (1993). Classroom management strategies: Are they setting events for coercion? Behavioral Disorders, 18(2), 92-102.

Shores, R. E., Jack, S. L., Gunter, P. L., Ellis, D. N., DeBrier, T. J., \& Wehby, J. H. (1993). Classroom interactions of children with behavior disorders. Journal of Emotional and Behavioral Disorders, 1, 27-39.

Sibley, S. A., Abbott, M. S., \& Cooper, B. P. (1969). Modification of the classroom behavior of a disadvantaged kindergarten boy by social reinforcement and isolation. Journal of Experimental Child Psychology, 1, 203-219.

Simcha-Fagan, O., Langner, T., Gersten, J., \& Eisenberg, J. (1975). Violent and antisocial behavior: A longitudinal study of urban youth (OCD-CB-480). Unpublished manuscript. Washington, DC: U.S. Office of Child Development.

Simpson, R. L., Miles, B. S., Walker, B. L., Ormsbee, C. K., \& Downing, J. A. (1991). Programming for aggressive and violent students. Reston, VA: Council for Exceptional Children.

Sloane, H. N., Johnstone, M. K., \& Bijou, S. W. (1967). Successive modification of aggressive behavior and aggressive fantasy play by management of contingencies. Journal of Child Psychology and Psychiatry, 8, 216-226.

Sprick, R., Sprick, M., \& Garrison, M. (1993). Interventions: Collaborative planning for students at risk. Longmont, CO: Sopris West.

Stainback, W., Stainback, S., \& Dedrick, C. (1979). Controlling severe maladaptive behaviors. Behavioral Disorders, 4, 99-115.

Sulzbacher, S. I., \& Houser, J. E. (1968). A tactic to eliminate disruptive behaviors in the classroom: Group contingent consequences. American Journal of Mental Deficiency, 73, 88-90.

Touchette, P. E., MacDonald, R. F., \& Langer, S. N. (1985). A scatter plot for identifying stimulus control of problem behavior. Journal of Applied Behavior Analysis, 18, 343-351.

Trice, A. D., \& Parker, F. C. (1983). Decreasing adolescent swearing in an instructional setting. Education and Treatment of Children, 6, 29-35.

Walker, H. M. (1983). Applications of response cost in school settings: Outcomes, issues, and recommendations. Exceptional Education Quarterly, 3(4), 47-55.

Walker, H. M. (1993). Antisocial behavior in school. Journal of Emotional and Behavior Problems, 2(1), 20-24.

Walker, H. M., \& Bullis, M. (1991). Behavior disorders and the social context of regular class integration: A conceptual dilemma. In J. W. Lloyd, N. N. Singh, \& A. C. Repp (Eds.), The regular education initiative: Alternative perspectives on concepts, issues, and models (pp. 75-94). Sycamore, IL: Sycamore Press.

Walker, H. M., Colvin, G., \& Ramsey, E. (1995). Antisocial behavior in school: Strategies for practitioners. Pacific Grove, CA: Brooks/Cole.

Walker, H. M., \& Severson, H. (1990). Systematic screening for behavior disorders. Longmont, CO: Sopris West.

Walker, H. M., Severson, H., Stiller, B., Williams, G., Haring, N. G., Shinn, M. R., \& Todis, B. (1988). Systematic screening of pupils in the elementary age range at-risk for behavior disorders: Development and trial testing of a multiple gating model. Remedial and Special Education, 9(3), 8-14. 
Walker, H. M., Shinn, M. R., O’Neill, R. E., \& Ramsey, E. (1987). A longitudinal assessment of the development of antisocial behavior in boys: Rationale, methodology, and first year results. Remedial and Special Education, 8(4), 7-16.

Walker, H. M., Stieber, S., \& O’Neill, R. E. (1990). Middle school behavioral profiles of antisocial and at-risk control boys: Descriptive and predictive outcomes. Exceptionality, 1, 61-77.

Walker, H. M., Stieber, S., Ramsey, E., \& O’Neill, R. E. (1991). Longitudinal prediction of the school achievement, adjustment, and delinquency of antisocial versus at-risk boys. $R e$ medial and Special Education, 12(4), 43-51.

Walker, H. M., Todis, B., Holmes, D., \& Horton, G. (1988). The Walker Social Skills curriculum: The ACCESS program. Austin, TX: PRO-ED.
Wasik, B. H., Senn, K., Welch, R. H., \& Cooper, B. R. (1969). Behavior modification with culturally deprived school children: Two case studies. Journal of Applied Behavior Analysis, 2, 181-194.

Webster, R. E. (1976). A time-out procedure in a public school setting. Psychology in the Schools, 13, 72-76.

Wehby, J. H. (1994). Issues in the assessment of aggressive behavior. Preventing School Failure, 38(3), 24-28.

White, O. R. (1986). Precision teaching-precision learning. Exceptional Children, 52, 522-534.

PERMISSIONS AND COPYRIGHT - All rights are reserved. No part of this publication may be reproduced, photocopied, faxed, stored in a retrieval system, or transmitted, in any form or by any means, electronic, mechanical, recording or otherwise, without the prior written permission of the publisher. • Back issues are available for sale. $\bullet$ Reproduction requires permission and payment of fees. It is illegal and a violation of federal copyright law to reproduce this publication without permission. Direct all inquiries to the permissions editor. 


\section{professional update}

\section{March 21-25, 1995}

National Association of School Psychologists Chicago Hilton Hotel

Contact: National Association of School Psychologists 8455 Colesville Rd., Suite 1000

Silver Spring, MD 20910

\section{April 5-9, 1995}

CEC Annual Conference Indiana Convention Center, Indianapolis

Contact: Council for Exceptional Children 1920 Association Drive

Reston, VA 22091
April 10-13, 1995

Fourth International Special Education Congress Birmingham, England

Contact: John Visser School of Education University of Birmingham Birmingham B15 2TT

England

FAX 021-414-4865

April 18-22, 1995

American Educational Research Association San Francisco Hilton Hotel

Contact: American Educational Research Association 1230 17th Street, NW

Washington, DC 20036 